\title{
Development of an Online Repository for Academic Research Works in FUTA
}

\author{
Christianah Oluwanifemi Itiola ${ }^{1,}$,, Babatunde Gabriel Iwasokun ${ }^{1}$, Johnson Damilola Adetooto ${ }^{2}$ \\ ${ }^{1}$ Department of Computer Science, School of Computing, Federal University of Technology, Akure, Nigeria \\ ${ }^{2}$ Department of Building, Obafemi Awolowo University, Ile-Ife, Nigeria
}

Email address:

christianahitiola@gmail.com (C. O. Itiola), maxtunde@yahoo.com (B. G. Iwasokun), adetooto@yahoo.com (J. D. Adetooto)

${ }^{*}$ Corresponding author

\section{To cite this article:}

Christianah Oluwanifemi Itiola, Babatunde Gabriel Iwasokun, Johnson Damilola Adetooto. Development of an Online Repository for Academic Research Works in FUTA. International Journal of Sustainability Management and Information Technologies.

Vol. 7, No. 1, 2021, pp. 22-26. doi: 10.11648/j.ijsmit.20210701.14

Received: March 10, 2021; Accepted: April 16, 2021; Published: June 25, 2021

\begin{abstract}
Research is part of the fundamental responsibilities needed in an academic institution. Therefore, it is expected that tertiary institutions should take importance in capturing, maintaining, and preserving their student's and staff's intellectual output; It will serve a significant role in disseminating scholarly materials, preserving, and diffusing the institution's research work. Hence, the research developed an institutional repository for academic research work for the Department of Computer Science, Federal University of Technology Akure (FUTA). The design made use of HTML (Hypertext mark-up language), CSS (Cascading style sheet), JAVASCRIPT, PHP (Hypertext pre-processor), and MySQL database. The system requirement for the design includes a processor (CPU) with 2.16 gigahertz (GHz), 4GB of RAM, Monitor Resolution 1024 X 768 or higher, a minimum of $20 \mathrm{~GB}$ available space on the hard disk, Intel Pentium processor, Keyboard, 64-bit operating system, and a Window 10 operating system. This design is expected to benefit the students and other users regarding the accessibility of materials to users and preserving student research. It will help create global visibility for the research works and collect content in a single location. However, the invention is limited to the sample size. Therefore, it recommends that a more advanced repository system be developed with time, which will capture studies across all faculties in the institution or across various institutions in the country.
\end{abstract}

Keywords: Frontend, Backend, Database, Institutional, Repository

\section{Introduction}

The internet had turned out to be a significant development of our days [1]. The internet has been defined as the communication superhighway that links, hooks, and transforms the entire world into a global village. Different individuals can quickly get in touch, see, or speak to one another and exchange information instantaneously from one point of the globe to another [2]. This technology has been proved to have reshaped the tertiary education practices to improve academics and overall data management [3-6]. Study [3] noted that educational institutions deal with many data and produce some high intellectual outputs. Hence requiring an online application to manage all data effectively [7].

Most tertiary institutions find it challenging to manage their intellectual output, including journal articles, conference papers, reports, theses \& dissertations, teaching materials, artwork, research notes, and research data [8-10]. Study [11] established that about $80-85 \%$ of universities' intellectual output is never accessible to the public. Consequently, research [12] noted that this could have resulted from the high cost of online journals, prohibiting the subscription to all or even most online academic journals.

However, research has proved that establishing an institutional repository will increase access to digital material, managed, organized, archived, and disseminated institutional data [13-17]. Most institutions in developing countries have established institutional repositories to enhance the visibility and impacts of research generated within the institution. [1820]. An institutional repository is an electronic system that captures, preserves, and provides digital work product access 
[21]. It collects, manages, and disseminates material produced at an institution [22] and maximizes the institutions' intellectual outputs [23].

Undergraduate students must conduct diverse research work in Nigerian universities as they progress through their final year [24]. In the Department of Computer Science, Federal University of Technology Akure, project writing is compulsory for all last year's students, and it is a requirement for graduation. Research project writing involves students or groups of students carrying out a study on a topic of interest [25]. The quality of the research is evaluated and graded by the department upon completion [26]. Over time, the department's academic research is not accessible to people outside the institution because the existing mode of operation is a manual one in which students have their research work kept in the department library and at the same time burn inside a disc (Compact Disk). These works can be lost due to fire outbreaks or floods.

Hence this study; to develop an institutional repository system that helps collect, preserves, manages, and provides access to intellectual products in the department. This research is significant because the department's research output will be accessible to people outside the institution. All the research work will be stored up in a database, and data will be gotten directly from the web application. Apart from this, users can also retrieve data on the web application using the Authors name, the Year the research was done, and the users' topic of interest.

\section{Methodology}

Before designing the proposed system, several literature materials were reviewed related to the design of an online repository academic research works sublime text used as the programming interface, HTML, CSS, JAVASCRIPT used for the system front end design. While MYSQL was used for the database, PHP was used for the server-side scripting used as the backend of the web application using the relational data model.

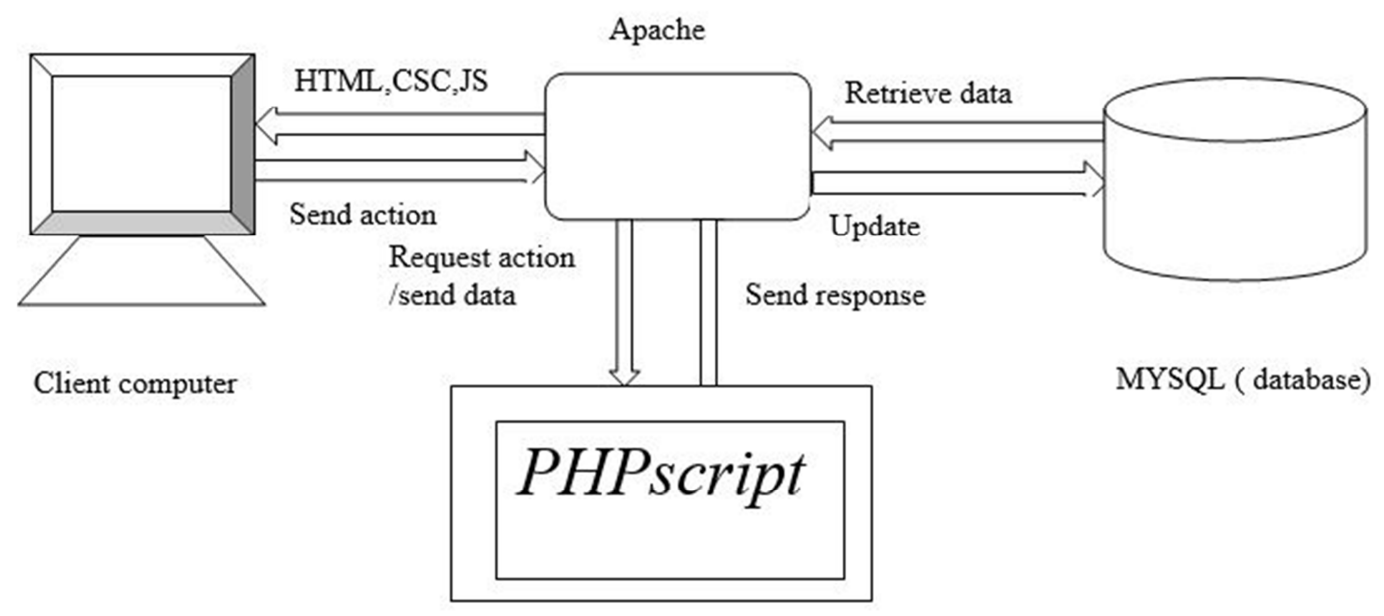

Figure 1. Architecture of a Typical Web Application.

\section{System Analysis and Design}

Conceptual design can be divided into two parts: the data model and the process model. The data model focuses on what is expected to be stored in the database, while the process model deals with how data that resides in the database has been processed. A relational database model was used; the data model is used to design the queries that will access and perform the operations on the tables.

For the project, MYSQL was used to build the database. And the architectural design of the system, which includes the interface also regarded as the frontend, was designed with HTML (HyperTextMarkup Language), CSS (Cascading Style Sheet), JS (JavaScript).

\subsection{Analysis of the System Understudy}

The Existing mode of operation is a manual one in which students have their research work kept in the department library and at the same time burn inside a disc (Compact Disk). The Federal University of Technology Akure (FUTA) in the Department of Computer Science, student research work has been handled in this form for an extended period, resulting in the inability to make the research work available to the general public go through it for knowledge acquisition.

\subsection{Constraints of the Existing System}

The system under study has many limitations in searching for research work done by the department; however, the following are some of the existing system's constraints.

A student might end up spending more time searching for research work manually.

The research stored up in a compact disk might end up getting corrupt.

People outside the university premises will not be able to access research carried out by the department.

Fire outbreak can ruin all research work stored up in a library. 


\subsection{System Design}

The Online Repository system is a web-based application that helps keep the department's research work more organized and safe. The design of this web application is justifiable as it is a more reasonable way to resolve the existing system's constraints. The benefits of the system include

This web application keeps the data in a more centralized way, available to all users simultaneously.

It is straightforward to manage all the student research work in a database.

No specific training is required for a student to be able to make use of the web application.

The research work becomes easily accessible to the public and its immediate environment.

Data stored in a database system is safer and more secure.

\subsection{Input Design}

The input design specifies how data flows into the system for processing. Input requirement is necessary for data entry and processing. The system uses MYSQL to controls and collects data and for storage.

\subsection{Interface Design}

The user interface will be designed with a Sublime text editor as it is a web application that will be viewed with a web browser. Below are the design interfaces for the various sections of the system.

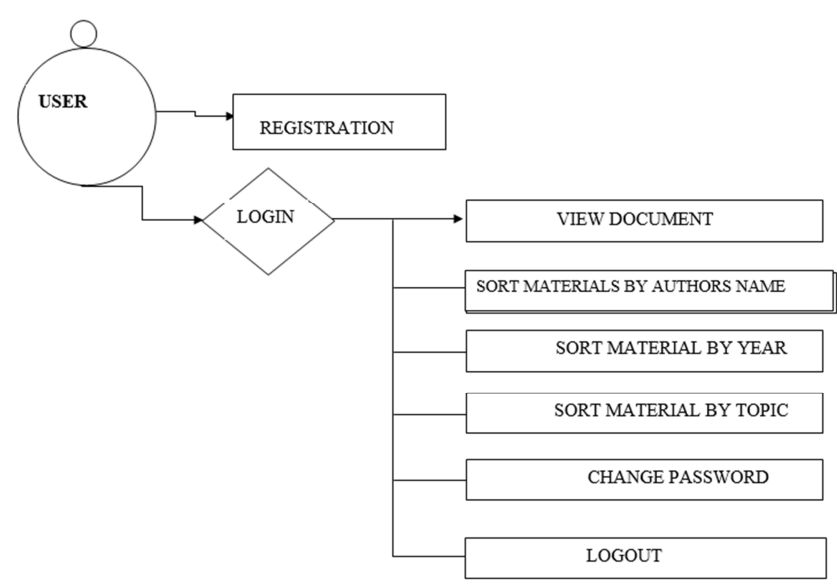

Figure 2. User view architecture.

\subsection{Output Design}

This aspect of the repository is to give a structural detail on how the output design looks like. All systems must have a means by which they display result in the form of output. The following design output views achieve this.

\subsection{System Database Design}

This is the design of the tables used in the designed system. MYSQL was used for the procedure. The tables below contain information about the users of the repository system.
Table 1. Users Table.

\begin{tabular}{lll}
\hline NAME & DATA TYPE & DESCRIPTION \\
\hline FULLNAME & VARCHAR (50) & USER'S FULL NAME \\
USERNAME & VARCHAR (25) & USER'S USERNAME \\
PASSWORD & VARCHAR (25) & USER'S PASSWORD \\
EMAIL & VARCHAR (50) & USER'S EMAIL \\
\hline
\end{tabular}

\subsection{Uploads Table}

This table will keep information about the project materials uploaded by the administrator.

Table 2. Uploads Table.

\begin{tabular}{lll}
\hline NAME & DATA TYPE & DESCRIPTION \\
\hline AUTHOR & VARCHAR (50) & THE AUTHOR OF THE MATERIAL \\
TOPIC & TEXT & THE TITLE OF THE MATERIAL \\
YEAR & VARCHAR (50) & THE YEAR THE PROJECT WAS \\
FILE & TEXT & PROJECT TO BE UPLOADED \\
\hline
\end{tabular}

\section{System Implementation}

\subsection{Hardware Support}

The hardware support for the implementation of the system comprises of the following;

Processor (CPU) with 2.16 gigahertz $(\mathrm{GHz})$

4GB of RAM

Monitor Resolution 1024 X 768 or higher

A minimum of $20 \mathrm{~GB}$ of available space on the hard disk

Intel Pentium processor

Keyboard

64-bit operating system

\subsection{Software Support}

The software support for the implementation of the system comprises of the following:

Sublime text editor

WAMP server.

My SQL database.

Window 10 operating system

\section{System Testing}

This is to ensure that the program runs smoothly by debugging every error associated with the new system's proper functioning. After that, we tested it after creating an account, inputting the username and password as it appears on the project's front side. We had to ensure that the mandatory field must be filled to increase efficiency, and errors detected were debugged during the testing process.

\section{System Review and Maintenance}

As the system is being put to use, users' requirements might end up changing with time. Thus equipment installation and implementation of a working system is not the supposed end of the system analysis and design; there is always a need for continuous review of the system's state to 
check if the users are no longer pleased. There is a need for maintenance to ensure that the system continually meets the objectives and achieves its specified goal.

\section{Installation Procedure}

The requirements needed to access the online repository system are mentioned in the hardware and software requirement section.

\section{User Guide}

This online web application is user-friendly, and the steps are simple to follow. On a successful loading, the index page pops up the system's interface with its menus. A user is expected to click on the "registration" link to supply some information for first-time registration. The login menu is used for authentication using the username and password provided during Successful registration authentication will prompt the display of a dashboard with the list of available documents which can be viewed and sorted for based on choice.

\section{Conclusion}

The study develops an institutional repository for academic research work for the Department of Computer Science, Federal University of Technology Akure. The design made use of HTML (Hypertext mark-up language), CSS (Cascading style sheet), JAVASCRIPT, PHP (Hypertext pre-processor), and MySQL database. The new system is expected to benefit the students and other users regarding the accessibility of materials to users and preserving student research. However, despite this research's immense contribution to the body of knowledge, care must be taken in generalizing the system output. It is limited to the Department of Computer Science in FUTA.

Therefore, the research recommends that a more advanced repository system be developed with time, which will capture studies across all faculties in the institution or across various institutions in the country.

\section{References}

[1] Grassegger, H., \& Krogerus, M. (2017). The data that turned the world upside down. Vice Motherboard, 28.

[2] Shitta, M. B. K. (2002). The impact of information technology on vocational and technical education for self-reliance. Journal of VOC \& Tech. Education, 1 (1).

[3] Naser, S. S. A., Al Shobaki, M. J., Amuna, Y. M. A., \& Al Hila, A. A. (2017). Trends of Palestinian Higher Educational Institutions in Gaza Strip as Learning Organizations.

[4] Apuke, O. D., \& Iyendo, T. O. (2017). Two sides of a coin: revisiting social networking sites' impact on students' performance in selected higher educational settings in Nigeria. Sci. Int, 29 (6), 1265-1275.
[5] Iyendo, O. T., \& Halil, Z. A. (2015). Computer-aided design (CAD) technology versus students' learning in architectural design pedagogy-a controversial topic review. International Journal of Development Research, 5 (1), 3152-3158.

[6] Manasijević, D., Živković, D., Arsić, S., \& Milošević, I. (2016). Exploring students' purposes of usage and educational usage of Facebook. Computers in Human Behavior, 60, 441450 .

[7] Oniovosa, O. E. (2016). Development of an Online Repository and Search Engine for Delsu Alumni. Asian Journal of Computer and Information Systems, 4 (3).

[8] Ukwoma, S. C., \& Mole, A. J. (2017). Utilisation of Institutional Repositories for Searching Information Sources, Self-Archiving, and Preservation of Research Publications in Selected Nigerian Universities. African Journal of Library, Archives \& Information Science, 27 (2).

[9] Islam, M., Uddin Munshi, N., Islam, N., \& Hossain, A. (2020). Digital preservation activities of institutional repositories in some selected public university libraries of Bangladesh: an analytical study. The Eastern Librarian, 25 (1), 24-40.

[10] Andayani, U. (2017). The collaboration between librarians and faculties in preserving and publishing the intellectual heritages through the institutional repositories: a case at Syarif Hidayatullah State Islamic University, Jakarta. Library Philosophy and Practice.

[11] The Open Citation Project. (2004). Open access and downloads ('hits') on citation impact: a bibliography of studies Retrieved Nov. 27, 2008, from http://opcit.eprints.org/oacitation-biblio.html.

[12] Warren, B. (2003). Current challenges and choices in scientific publication Baylor University Medical Centre Proceedings, v 16 (4), Retrieved April. 08, 2021 from http://www.baylorhealth.edu/proceedings/16_4/16_4_warren. pdf.

[13] Posavec, K., Celjak, D., \& Musap, L. J. (2020). Role of a Croatian National Repository Infrastructure in Promotion and Support of Research Data Management. Data Science Journal, 19 (1).

[14] Kodua-Ntim, K., \& Fombad, M. C. (2020). Strategies for the use of open access institutional repositories at universities in Ghana. Library Management.

[15] Essel, H. B., Lamptey, R. B., Tachie-Menson, A., \& Bonsu, F. M. (2019). Adopting a Logic Framework for the Evaluation of the Operational Processes and Outcomes of KNUST Space on Research, Learning, and Teaching: A Case of Empirical Research Output by Academic Staffs and Students. Library Philosophy and Practice, 1-25.

[16] Ukwoma, S. C., \& Okafor, V. N. (2017). Institutional repository in Nigerian universities: trends and development. Library Collections, Acquisitions, \& Technical Services, 40 (1-2), 46-57.

[17] Okon, R., Eleberi, E. L., \& Uka, K. K. (2020). A Web-Based Digital Repository for Scholarly Publication. Journal of Software Engineering and Applications, 13 (4), 67-75.

[18] Katayoon, K., \& Abrizah, A. (2017). Librarians' Role as Change Agents for Institutional Repositories: A Case of Malaysian Academic Libraries. Malaysian Journal of Library \& Information Science, 15 (3), 121-133. 
[19] Nunda, I., \& Elia, E. (2019). Institutional repositories adoption and use in selected Tanzanian higher learning institutions. International Journal of Education and Development using ICT, 15 (1).

[20] Masor, M. H., \& Kassim, N. A. (2020). Measuring Success Factors and Performance of Institutional Repositories. Masor, MH, \& Kassim, NA (2020). Measuring success factors and performance of institutional repositories. Journal of Administrative and Business Studies, 6 (3), 78-83.

[21] Roy, B. K. (2021). Institutional Digital Repositories: a systematic review of the literature. Library Philosophy and Practice, 1-12.

[22] Nyangoya, B. (2020). Role of Librarians in mitigating information explosion in academic libraries: the case study of the Jomo Kenyatta Memorial Library-UON (Doctoral dissertation, University of Nairobi).
[23] Nwokedi, V. C., \& Nwokedi, G. I. (2018). Open Access Institutional Repositories in Academic and Research Institutions in Nigeria: A Review of Benefits and Challenges.

[24] Apuke, O. D., \& Iyendo, T. O. (2018). University students' usage of the internet resources for research and learning: forms of access and perceptions of utility. Heliyon, 4 (12), $\mathrm{e} 01052$.

[25] Tofi, S. T. (2019). Perceived impact of internet services on computer science undergraduate research in universities in Benue State, Nigeria. Library Philosophy and Practice, 1-131.

[26] Fatoki, O. C. (2004). Impact of Library Resources and the Internet on Undergraduate Students Research, University of Ibadan, Nigeria. Nigerian Libraries. 38 (1): 21-33. 